\title{
REMOVAL OF RHODAMINE FROM AQUEOUS SOLUTIONS USING NATURAL ZEOLITE
}

\author{
LACRIMIOARA SENILA ${ }^{\mathrm{a}, 1}$, EMILIA NEAG ${ }^{\mathrm{a}, 1}$, \\ DANIELA ALEXANDRA SCURTUa, OANA CADAR ${ }^{a}$, ANCA BECZE $^{a}$, \\ CALIN HOREA TOMOIAG ${ }^{b}$, MARIN SENILA ${ }^{\text {a* }}$
}

\begin{abstract}
The aim of this study was to evaluate the adsorption of rhodamine $B(R B)$ from synthetic water using natural zeolites from Romania. The adsorption capacity of zeolite for RB removal was improved by heat treatment at 200,400 and $600{ }^{\circ} \mathrm{C}$. The chemical and structural characterization of untreated and thermally treated zeolites was performed using advanced techniques such as X-ray diffraction (XRD), scanning electron microscopy (SEM) and Brunauer-Emmett-Teller (BET) analysis. The adsorption behavior of RB on activated zeolites was studied using Langmuir, Freundlich and DubininRadushkevich isotherms. The thermally treated zeolite at $200^{\circ} \mathrm{C}$ gave the highest adsorption efficiency (97.9\%) for RB adsorption from aqueous solutions. According to the obtained results, it can be concluded that thermally treated zeolite can be used as an effective adsorbent for the removal of RB from wastewater.
\end{abstract}

Keywords: zeolites, rhodamine $B$, thermal activation

\section{INTRODUCTION}

A large quantity of pollutants is discharged in the environment during the textile dying process. Among the chemical pollutants, dyes have carcinogenic and mutagenic effects and are difficult to remove from wastewater $[1,2]$. The dye industry is very diverse and heterogenous and the chemical composition of wastewater is very complex due to the use of raw materials and technological processes [3]. Rhodamine $B(R B)$ is used in many textile applications and

\footnotetext{
a INCDO-INOE 2000, Research Institute for Analytical Instrumentation, Donath 67, 400293, Cluj-Napoca, Romania; Tel: +40-264-420590; Fax: +40-264-420667

b Tomas Prodimpex SRL, 18 B-dul Eroilor Street, Cluj-Napoca, Romania

1 Authors with equal contribution

* Corresponding author: marin.senila@icia.ro
} 
can cause ecotoxicological problems for human health. Consequently, its discharging into water can cause environmental problems. Therefore, it is imperative to effectively remove the RB dye from wastewater due to its polluting effect $[4,5]$.

Various methods, such as advanced oxidation, biodegradation, coagulation, sedimentation, membrane technology, ozonation and adsorption were applied for the removal of dyes from wastewater. Also, numerous adsorption materials, like active coal, carbon materials, minerals, polymers and zeolites were used for the adsorption of dye from wastewater [6, 7].

In recent years, activation methods, such as acid treatment, base treatment, etc. were investigated in order to improve the adsorption properties of zeolites.

Zeolites are crystalline hydrated aluminosilicates of alkali and alkaline earth cations, usually used for the adsorption of different pollutants (heavy metals, phenols, ammonium, organic pollutants, antibiotics, etc.) from wastewater. The most common mineral of zeolites is clinoptilolite. Clinoptilolite has the capacity to adsorb cations through ion exchange process due to the presence of negative charge of the three-dimensional framework created by silicon, aluminum and oxygen. The factors that affect the adsorption of dyes are Si:Al ratio, ionic potential, size of exchangeable cations, etc. [8, 9, 10].

Generally, natural zeolites are activated physically, chemically or by the combination of both processes in order to increase the adsorption capacity [11]. In the literature, the adsorption of RB into synthesized zeolite or chemically activated zeolites was reported $[12,13,14]$.

This paper aimed to study the behavior of natural zeolites from Romania under thermal activation for RB adsorption from aqueous solutions. Also, the mechanism of the RB adsorption process was studied.

\section{RESULTS AND DISCUSSION}

\section{Scanning electron microscopy (SEM) of untreated and thermally treated zeolites}

The morphological structure and chemical composition of untreated and thermally treated zeolites at $200^{\circ} \mathrm{C}(\mathrm{TZ}-200), 400^{\circ} \mathrm{C}(\mathrm{TZ}-400)$ and $600^{\circ} \mathrm{C}$ (TZ-600) was investigated by using scanning electron microscopy-energy dispersive X-ray (SEM-EDX) analysis (Figure 1). The SEM images showed that the increasing temperature changed the zeolite structure. The morphology of natural zeolite (NZ) showed well-defined agglomerate particles and uniform dispersion, whereas the morphology of thermally treated zeolite presented a 
lamellar structure, with the exception of TZ-600, when the alteration of zeolite structure was observed. This can be attributed to the dehydration process and the stress produced by the increase of temperature. According to the study of Cruciani C. [15], the heating treatment of zeolites led to some structural modifications of internal structure. Moreover, a direct correlation between the stability index and Si:Al ratio was established.

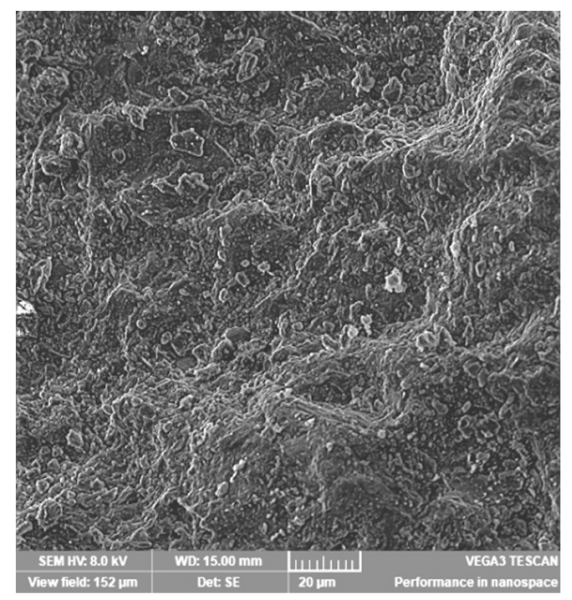

(a)

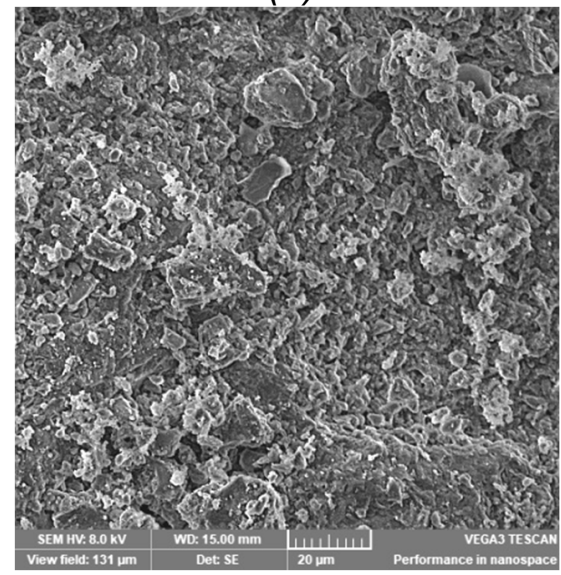

(c)

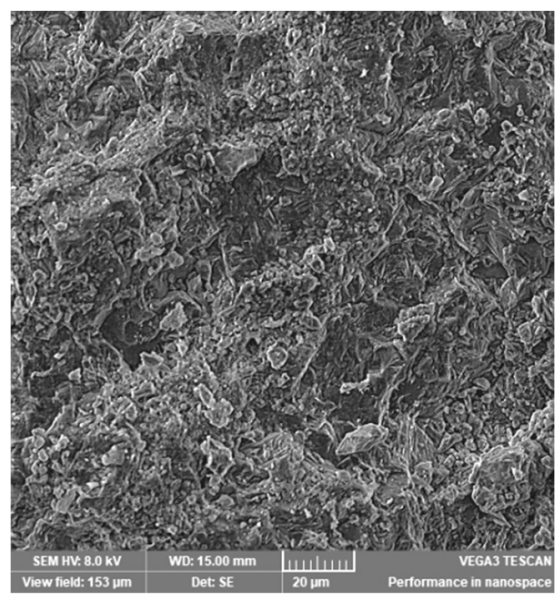

(b)

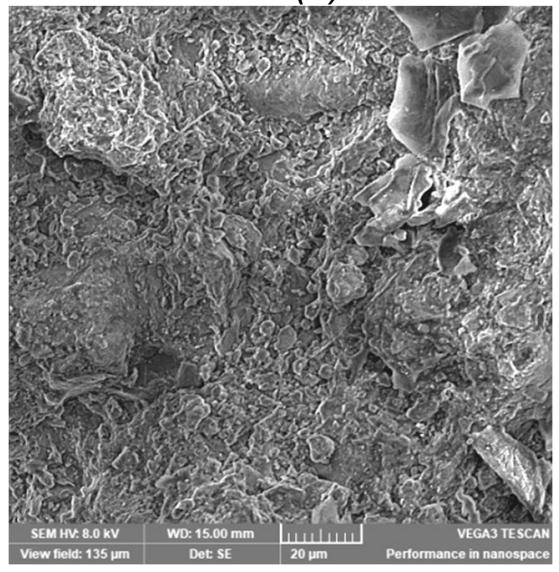

(d)

Figure 1. SEM images of zeolites: (a) NZ, (b) TZ-200, (c) TZ-400 and (d) TZ-600 
LACRIMIOARA SENILA, EMILIA NEAG, DANIELA ALEXANDRA SCURTU, OANA CADAR, ANCA BECZE, CALIN HOREA TOMOIAG, MARIN SENILA

\section{Physical and chemical characteristics of studied zeolites}

Table 1. Physical characteristics of the studied zeolites

(Data represents mean \pm standard deviation, $n=3$ ).

\begin{tabular}{|c|c|c|c|c|}
\hline Element & NZ & TZ-200 & TZ-400 & TZ-600 \\
\hline $\mathrm{pH}(\mathrm{pH}$ units) & $8.33 \pm 0.1$ & $8.25 \pm 0.1$ & $8.00 \pm 0.2$ & $8.12 \pm 0.1$ \\
\hline Conductivity $(\mu \mathrm{S} / \mathrm{cm})$ & $82.3 \pm 0.8$ & $200.4 \pm 0.6$ & $301.5 \pm 0.5$ & $290.1 \pm 0.6$ \\
\hline $\mathrm{CEC}(\mathrm{meq} / \mathrm{g})$ & $1.28 \pm 0.6$ & $1.18 \pm 0.8$ & $0.86 \pm 0.7$ & $0.53 \pm 0.6$ \\
\hline $\mathrm{SA}\left(\mathrm{m}^{2} / \mathrm{g}\right)$ & $28.1 \pm 0.1$ & $54.2 \pm 0.2$ & $40.3 \pm 0.1$ & $36.2 \pm 0.1$ \\
\hline
\end{tabular}

CEC- cation exchange capacity, SA - specific surface area

The physical properties of the studied zeolites are presented in Table 1. The increase of surface area leads to a better adsorption capacity. The Brunauer-Emmett-Teller (BET) surface increased from 28.1 to $54.2 \mathrm{~m}^{2} / \mathrm{g}$ (for zeolite activated at $200^{\circ} \mathrm{C}$ ), and slowly decreased for the treated zeolites at 400 and $600^{\circ} \mathrm{C}$. This is explained by the modification of the zeolite structure at high temperature, leading to the loss of dyes adsorption sites.

Table 2. Content of oxides (\%) from the studied zeolites

\begin{tabular}{|c|c|c|c|c|}
\hline Element & $\mathbf{N Z}$ & $\mathbf{T Z - 2 0 0}$ & $\mathbf{T Z - 4 0 0}$ & TZ-600 \\
\hline $\mathrm{K}_{2} \mathrm{O}$ & 3.10 & 2.42 & 2.31 & 2.21 \\
\hline $\mathrm{CaO}$ & 2.53 & 2.50 & 2.40 & 1.93 \\
\hline $\mathrm{MgO}$ & 0.84 & 0.83 & 0.75 & 0.70 \\
\hline $\mathrm{Fe}_{2} \mathrm{O}_{3}$ & 1.07 & 1.21 & 1.18 & 1.29 \\
\hline $\mathrm{SiO}_{2}$ & 65.4 & 64.3 & 72.8 & 77.2 \\
\hline $\mathrm{Al}_{2} \mathrm{O}_{3}$ & 13.4 & 13.8 & 11.5 & 10.8 \\
\hline $\mathrm{Na}_{2} \mathrm{O}$ & 0.67 & 0.75 & 0.72 & 0.68 \\
\hline $\mathrm{LOI}$ & 12.9 & 7.30 & 8.34 & 5.19 \\
\hline
\end{tabular}

LOI -loss of ignition

The composition of oxides $\left(\mathrm{SiO}_{2}, \mathrm{Al}_{2} \mathrm{O}_{3}, \mathrm{~K} 2 \mathrm{O}, \mathrm{CaO}, \mathrm{Fe}_{2} \mathrm{O}_{3}, \mathrm{Na}_{2} \mathrm{O}\right.$ and $\mathrm{MgO}$ ) in the studied samples was presented in Table 2. The chemical analyses indicate low contents of $\mathrm{Na}_{2} \mathrm{O}, \mathrm{MgO}, \mathrm{K}_{2} \mathrm{O}$ and $\mathrm{Fe}_{2} \mathrm{O}_{3}$. The thermal treatment led to changes in the mineral compositions of zeolites. The $\mathrm{Al}_{2} \mathrm{O}_{3}$ content gradually decreased with increasing the activation temperature. The results showed that the dealumination process occurred at high temperature.

\section{Adsorption performance of zeolites for RB removal}

The removal of RB from the aqueous solution has been investigated using thermally treated clinoptilolite as adsorbent. The adsorption of RB into zeolites was investigated by varying the following parameters: initial dye concentration, dosage of adsorbent, thermal activation of zeolites. 
Figure 2 illustrates the removal efficiency $E(\%)$ versus the initial concentration for experiments performed for RB adsorption. An increase in zeolite quantity led to an increase in the RB removal.

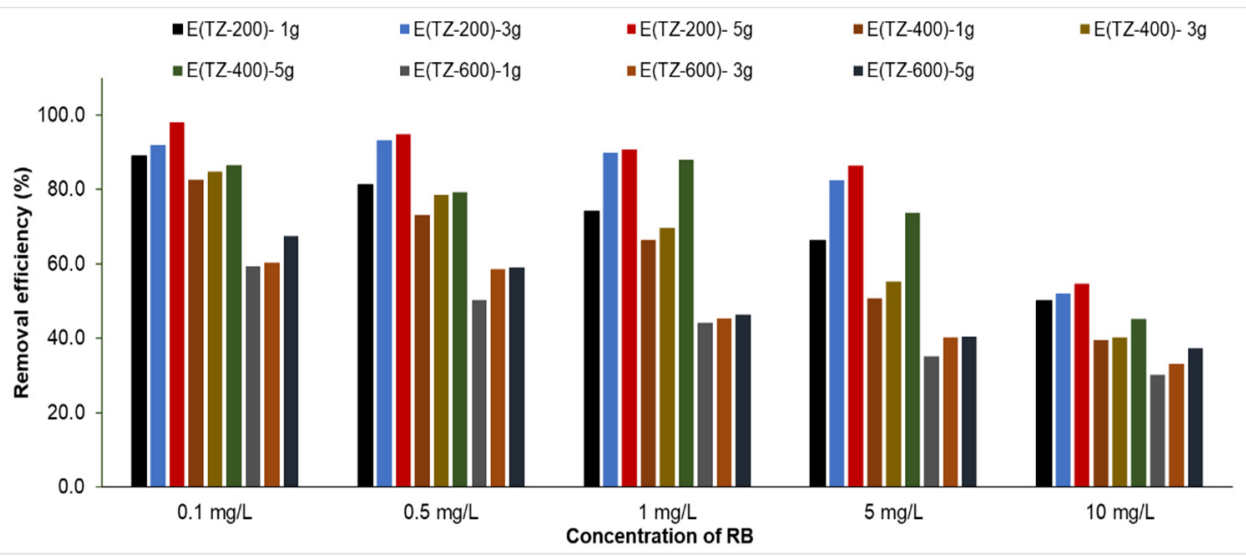

Figure 2. The removal efficiency of RB under different experimental conditions

The temperature used for the activation of zeolites influenced the removal efficiency. As depicted in Figure 2, the RB removal efficiency increased with the increase of zeolite quantity. The highest removal efficiency $(98.0 \%)$ was obtained using $5 \mathrm{~g}$ of zeolite activated at $200^{\circ} \mathrm{C}$. The lowest removal efficiency $(30.2 \%)$ was obtained using $1 \mathrm{~g}$ of zeolite activated at $600^{\circ} \mathrm{C}$. The adsorption capacity decreased by increasing initial concentration of RB.

Figure 3 displays the XRD (X-ray diffraction) patterns of the thermally activated zeolite and the TZ zeolite adsorbed with different quantities of RB.

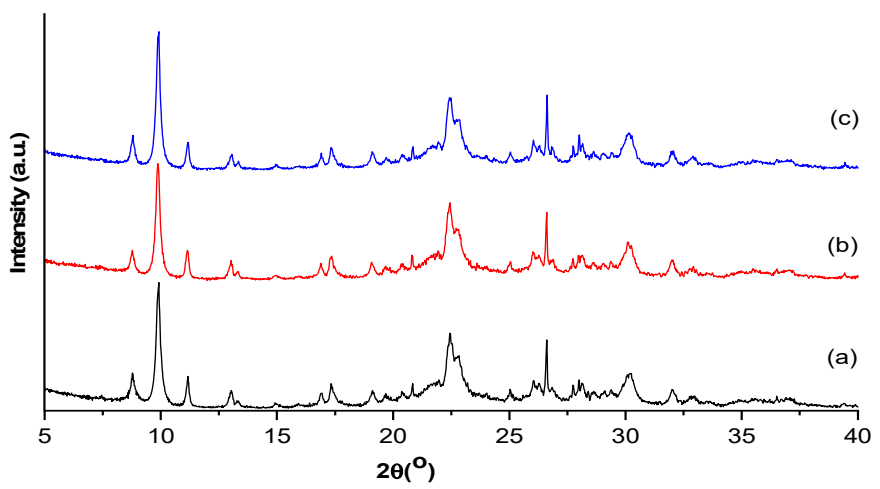

Figure 3. XRD diffraction patterns of zeolites: (a) TZ-200, (b) TZ-200 with $0.1 \mathrm{mg} / \mathrm{l}$ of RB, (c) TZ-200 with $10 \mathrm{mg} / \mathrm{L}$ of RB 
The XRD analysis reveals the presence of clinoptilolite-Na as a major crystalline phase, accompanied by quartz, muscovite and albite. The XRD of the initial sample is similar to those of adsorbed zeolite with different amounts of RB, indicating that the adsorption of dyes did not influence their crystal structure. The obtained results proved that the crystalline structure of zeolites was stable. The following series was depicted based on the degree of crystallinity: $74.2 \%(T Z-200)>72.4 \%$ (TZ-200, $0.1 \mathrm{mg} / \mathrm{L})>71.6 \%$ (TZ-200, $10 \mathrm{mg} / \mathrm{L}$ ). The degree of crystallinity decreased with the increase of the RB initial concentration, due to the adsorption of RB molecules into the zeolite structure, suppressing the diffraction of the framework atoms of zeolite. The same remarks were observed by Ji et al. [16] and Ertan et al. [17] for the adsorption of methylene blue dye onto synthetized zeolite.

\section{Adsorption isotherms}

The Langmuir, Freundlich and Dubinin-Radushkevich isotherm constants and the determination coefficients $\left(R^{2}\right)$ obtained from the slope and the intercept of the linear plots are presented in Table 3.

Table 3. Equilibrium isotherm constants obtained for RB adsorption on treated zeolites.

\begin{tabular}{|c|c|c|c|c|}
\hline \multirow[b]{2}{*}{ Isotherm model } & \multicolumn{3}{|c|}{ Parameters } & \multirow[b]{2}{*}{$\mathbf{R}^{2}$} \\
\hline & Symbol & $\begin{array}{c}\text { Unit of } \\
\text { measurement }\end{array}$ & Value & \\
\hline \multirow{2}{*}{ Langmuir } & $q_{\max }$ & $\mathrm{mg} / \mathrm{g}$ & 0.03 & \multirow{2}{*}{0.9667} \\
\hline & $K_{L}$ & $\mathrm{~L} / \mathrm{mg}$ & 41 & \\
\hline \multirow{2}{*}{ Freundlich } & $\mathrm{s}$ & - & 2 & \multirow{2}{*}{0.9689} \\
\hline & $\mathrm{K}_{\mathrm{F}}$ & $m g^{(1-1 / n)} L^{1 / n} / g^{1}$ & 0.07 & \\
\hline \multirow{2}{*}{$\begin{array}{c}\text { Dubinin- } \\
\text { Radushkevich }\end{array}$} & $\beta$ & $\mathrm{mol}^{2} / \mathrm{kJ}^{2}$ & $3 \cdot 10^{-9}$ & \multirow{2}{*}{0.9750} \\
\hline & $\mathrm{E}_{\mathrm{L}}$ & $\mathrm{kJ} / \mathrm{mol}$ & 13 & \\
\hline
\end{tabular}

$q_{\max }$ is the maximum amount of RB adsorbed per gram of activated zeolite, $\mathrm{K}_{\mathrm{L}}$ - Langmuir constant, $\mathrm{s}$ - Freundlich constant, $K_{F}$ - Langmuir constants, $\beta$-Dubinin-Radushkevich constant, $E_{L}$ - mean free energy.

The Freundlich isotherm suggested that zeolite has a heterogenous surface with nonuniform distribution of heat over the zeolite surface. The value $s$ is 2 , indicating a favorable adsorption of RB on zeolite.

The Dubinin-Radushkevich isotherm indicated a chemical chemisorption process of adsorption of RB onto zeolite due to the $E_{L}$ value $(<16 \mathrm{~kJ} / \mathrm{mol})$ according to Sari et al. [18]. 


\section{CONCLUSIONS}

The thermally activated zeolites at three temperatures $(200,400$ and $600{ }^{\circ} \mathrm{C}$ ) were used for RB adsorption. The obtained results indicated that the thermal treatment improved the adsorption performance of zeolites for RB removal, but the activation temperature should be lower than $400^{\circ} \mathrm{C}$ to prevent the modification of its crystalline structure. It was found that the Freundlich isotherm model described the mechanism of RB adsorption process. The Dubinin-Radushkevich isotherm indicated that RB adsorption onto zeolite was characterized by a chemisorption process. The present study demonstrated that natural zeolites could be used as a promising adsorbent material for the removal of dyes from aqueous solutions.

\section{EXPERIMENTAL SECTION}

\section{Chemicals and materials}

The NZ obtained from Chiloara quarry; Salaj County, Romania was crushed and sieved in order to obtain 1-3 mm, then washed several times with distilled water to remove the impurities.

All used chemicals were of analytical reagent grade and were purchased from Merck (Darmstadt, Germany). RB was purchased from Sigma Aldrich (Darmstadt, Germany). All solvents used were of HPLC grade. Deionized water used in dilutions was obtained by using a Milli-Q purification system (Millipore, Bedford, MA, USA).

\section{Activation of zeolites}

The NZ was activated at 200,400 and $600^{\circ} \mathrm{C}$ for $4 \mathrm{~h}$ obtaining the following samples: TZ-200, TZ-400 and TZ-600.

\section{Physical and chemical characterization of zeolites}

The determination of metals was carried-out by the digestion of zeolites with a mixture of $65 \% \mathrm{HNO}_{3}$ and $37 \% \mathrm{HCl}$ (ratio v:v $=1: 3$ ) in closed polytetrafluoroethylene (PTFE) vessels, using a microwave digestion system (Speedwave Xpert, Berghof, Eningen, Germany), followed by inductively coupled plasma optical emission spectroscopy (ICP-OES) [18]. The oxides from zeolites were calculated according to Senila et al. [19] studies. The LOI was determined gravimetrically according to Cadar et al. [11]. 
The untreated and thermally treated zeolites were characterized by Xray diffraction (D8 Advance diffractometer (Bruker, Karlsruhe, Germany), SEM analysis with EDX detector (SEM VEGAS 3 SBU, Tescan, Brno-Kohoutovice, Czech Republic), and BET specific area (Sorptomatic 1990 apparatus, Thermo Electron Corporation). The determination of CEC was determined according to Gualtieri et al. method (1999) [20] and the $\mathrm{pH}$ was determined using a Seven Excellence multiparameter (Mettler Toledo, Switzerland).

\section{Adsorption experiments}

A stock solution of $1 \mathrm{~g} / \mathrm{L} \mathrm{RB}$ was prepared by dissolving the salts in distilled water. The used concentrations $(0.1,0.5,1,5$ and $10 \mathrm{mg} / \mathrm{L})$ were prepared by diluting the concentrated stock solutions.

The experiments were performed in batch mode, by contacting different quantities (1-5 g) of NZ and thermally TZ at 200,400 and $600^{\circ} \mathrm{C}$, having particle sizes of $1-3 \mathrm{~mm}$ with $100 \mathrm{~mL}$ containing $\mathrm{RB}$ initial concentrations in the range of 0.1-10 $\mathrm{mg} / \mathrm{L}$. All the adsorption experiments were performed at room temperature $20 \pm 4^{\circ} \mathrm{C}$ for $240 \mathrm{~min}$. The samples were centrifuged at $4000 \mathrm{rpm}$ for $10 \mathrm{~min}$. The RB concentrations were determined using Lambda 25 UV-VIS spectrophotometer (Perkin Elmer, Woodbridge, ON, USA) at $552 \mathrm{~nm}$. The adsorption capacity $\mathrm{q}_{\mathrm{e}}(\mathrm{mg} / \mathrm{g})$ and the removal efficiency $\mathrm{E}(\%)$ were calculated according to equations (1) and (2), respectively.

$$
\begin{gathered}
\mathrm{q}_{\mathrm{e}}=\frac{\left(C_{i}-C_{e}\right)}{m} \frac{V}{1000} \\
\text { \%RB removal }=\left(\mathrm{C}_{\mathrm{i}}-\mathrm{C}_{\mathrm{e}}\right) \times 100 / \mathrm{C}_{\mathrm{i}}
\end{gathered}
$$

where: $C_{i}$ is the initial concentration, $C_{e}$ is the concentration of RB after the adsorbtion of zeolites, $\mathrm{m}$ is the mass of dried zeolites, $\mathrm{V}$ is the solution volume $(\mathrm{mL})$.

\section{Equilibrium studies}

The equilibrium adsorption data of RB on zeolite were analyzed by using the Langmuir, Freundlich and Dubini-Radushkevich isotherms. The linear forms of Langmuir and Freundlich isotherms are given in Egs. (3) and (4), respectively [21]:

$$
\frac{1}{q_{e}}=\frac{1}{q_{\max } K_{L} C_{e}}+\frac{1}{q_{\max }}
$$




$$
\log q_{e}=\log K_{F}+\frac{1}{S} \log C_{e}
$$

where, $K_{F}$ and $s$ are isotherm constants which indicate the capacity and intensity of the adsorption [22, 23]. If the $s$ value lies between $1<s<10$ it indicates a favorable adsorption process [21].

The Dubinin-Radushkevich isotherm suggests that the adsorption process follows a pore filling, having a multilayer character. Its equation is given as follows [24]:

$$
\begin{aligned}
& \ln q_{e}=\ln q_{\max }-\beta \varepsilon^{2} \\
& \varepsilon= R \operatorname{Rln}\left(1+\frac{1}{C_{e}}\right) \\
& E_{L}=\frac{1}{\sqrt{-2 \beta}}
\end{aligned}
$$

where, $R$ is the gas constant $(8.314 \mathrm{~J} \mathrm{~mol} / \mathrm{K})$ and $T$ is the absolute temperature $(K), \varepsilon$ is the Polanyi potential [24].

The $E_{L}$ value indicates whether the adsorption process of $\mathrm{RB}$ on activated zeolite is chemical $\left(8<E_{L}<16 \mathrm{~kJ} / \mathrm{mol}\right)$, or physical $\left(E_{L}<8 \mathrm{~kJ} / \mathrm{mol}\right)$ $[24,25,26]$.

\section{ACKNOWLEDGEMENTS}

This research was funded by the Competitiveness Operational Programme of the Ministry of European Funds, contract no. 7/01.09.2016, code MY SMIS 105654.

\section{REFERENCES}

1. R. Pelalak; R. Soltani; Z. Keidari; R.E. Malekshah; M. Aallaei; A. Marjani; M. Rezakazemi; T.A. Kurniawan; S. Shirazian; J. Mol. Liq., 2021, 322, 114812.

2. W. Li; B. Mu; Y. Yang; Bioresour. Technol., 2019, 277, 157-170.

3. J. Bu; L. Yuan; N. Zhang; D. Liu; Y. Meng; X. Peng; Diam. Relat. Mater., 2020, 101, 107604.

4. F. Motahari; M.R. Mozdianfard; M. Salavati-Niasari; Process Saf. Environ. 2015, 93, 282-292.

5. M. Rahmani; M. Kaykhaii; M. Sasani; Spectrochim. Acta A: Mol. Biomol. Spectrosc., 2018, 188, 164-169. 
LACRIMIOARA SENILA, EMILIA NEAG, DANIELA ALEXANDRA SCURTU, OANA CADAR, ANCA BECZE, CALIN HOREA TOMOIAG, MARIN SENILA

6. S. Mishra; L. Cheng; A. Maiti; J. Environ. Chem. Eng., 2021, 9, 104901.

7. M.F. Chowdhury; S. Kladaker; F. Sarker; A. Islam; M.T. Rahman; M.R. Awual; J. Mol. Liq., 2020, 318, 114061.

8. M.A. Farghali; M. M. Abo-Aly; T.A. Salaheldin; Inorg. Chem. Commun., 2021, 126, 108487.

9. H. Mittal; R. Badu; A.A. Dabbawala; S. Stephen; S.M. Alhassan; Colloids Surf. $A, 2020,586,124161$.

10. S. Sivalingam; S. Sen; J. Taiwan Inst. Chem. Eng., 2019, 96, 305-314.

11. O. Cadar; M. Senila; M.A. Hoaghia; D.A. Scurtu; I. Miu; E.A. Levei; Molecules, 2020, 25(11), 2570.

12. F. Alakhras; E. Alhajri; R. Haounati; H. Ouachtak; A.A. Addi; T.A. Saleh; Surf. Interfaces, 2020, 20, 100611.

13. Z. Cheng; Y. Li; Z. Liu; Ecotoxicol. Environ. Saf., 2018, 148, 585-592.

14. Z. Cheng; Y. Li; Z. Liu; J. Alloy. Compd., 2017, 708, 255-263.

15. C. Cruciani; J. Phys. Chem. Solids, 2006, 67, 1994.

16. Y. Ji; F. Xu; W. Wei; H. Gao; K. Zhang; G. Zhang; Y. Xu; P. Zhang; J. Solid State Chem., 2021, 295, 121917.

17. B. Ertan; S. Gurkok; D. Efe; Stud U Babes-Bol. Che., 2020, 4, 109-123.

18. A. Sarl; M. Tuzen; J. Hazard. Mater., 2008, 152, 302-308.

19. M. Senila; O. Cadar; L. Senila; A. Hoaghia; I. Miu; Molecules, 2019, 24(22), 4023.

20. A.F. Gualtierei; E. Marchi; E. Passaglia; Stud. Surf. Sci. Catal., 1999, 125, 707-713.

21. I. Langmuir; J. of Am. Chem. Soc., 1916, 38, 2221-2295.

22. N. Ayawei; E.A. Newton; D. Wankasi; J. Chem., 2017, Article ID 3039817.

23. Y. Zhuang; F. Yu; J. Chen; J. Ma; J. Environ. Chem. Eng., 2016, 4(1), 147-156.

24. M.M. Dubini; Chem. Rev., 1960, 60, 235-241.

25. X. Hu; X. Du; Molecules, 2019, 24, 1449.

26. N.T. Thanh; T.V. Thien; P.D. Du; C.V.T. Thanh; T.X. Mau; D.Q. Khieu; J. Environ. Chem. Eng., 2018, 6(2), 2269-2280. 